Volume 8, No. 7, July - August 2017

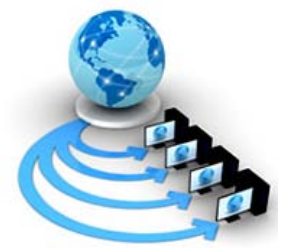

International Journal of Advanced Research in Computer Science

TECHNICAL NOTE

Available Online at www.ijarcs.info

\title{
MOBILE APPLICATION FOR VEHICULAR AUTO LOCKING SYSTEM
}

\author{
Mayank Dogra \\ Students of Department of computer Science \\ Faculty of Engineering and Technology \\ Manav Rachna International University \\ Neeraj Bhateja \\ Students of Department of computer Science \\ Faculty of Engineering and Technology \\ Manav Rachna International University
}

\author{
Yuvraj Singh \\ Students of Department of computer Science \\ Faculty of Engineering and Technology \\ Manav Rachna International University
}

\author{
Dr. Meeta Singh \\ Assistant Professor \\ Department of Computer Science and Engineering \\ Faculty of Engineering and Technology \\ Manav Rachna International University \\ Faridabad.
}

\begin{abstract}
This paper describes the development of a Vehicular Auto locking system which will allow the end-users to lock, unlock and check the lock status of their vehicle with the help of a Android phone application. The developed application would be accessible only to the registered users of our application. The application would allow the new users to register on the application for accessing the services provided by the application.
\end{abstract}

Keywords: Vehicular, Auto, Locking, Unlock,Android,Phone,Application

\section{INTRODUCTION}

In today's world ,[1] everyone tends to keep up with the advancement in technology.

Buying an automobile is a big investment for a lot many people, and this is the reason people are concerned about advancement in various technologies in the automobile industry . This makes sure that the Automobile Industry is not left behind in this aspect .

Therefore, these automobile companies have witnessed a major economical growth in the past few years due to their latest up to date technological features such as automation in the vehicles to provide a user friendly experience to their customers. Imagine the world with our vehicle locking system via a mobile application using Bluetooth technology will be a great advantage for automobile industries and their customers in terms of human energy and time consuming. It will eventually be free of charge with no additional costs involved form the automobile manufacturer .

Therefore, in this project we will be implementing and developing a system from which a customer can lock or unlock his/her vehicle using a mobile phone application . The system will be constructed by integrating parts of both , hardware as well as software. It can be developed to get an easy access to our car i.e. to unlock \& lock the car doors with the help of our smart phone so that the owner will not have to search for their keys in their pockets or bags and can simply access their car by tapping the smart phone screen. This will also help the user to find their car in a parking lot. This thought will come true with the help of a Bluetooth device. Nowadays it is needed to carry keys and keep it safely, and if lost then suffer the cause. But this will not be the scenario anymore, there will be no need to carry our keys when we will be able to enter into the car with just a smart phone tap.

\section{Arduino UNO}

Arduino UNO [2](Figure.1) is a microcontroller board based on the ATmega328P (datasheet). Arduino Uno simply reads and input and gives corresponding ouput, thus, turning an LED on.,thus sending signals to our servo motor And by defining the certain angle in Arduino IDE by which motor will rotate.

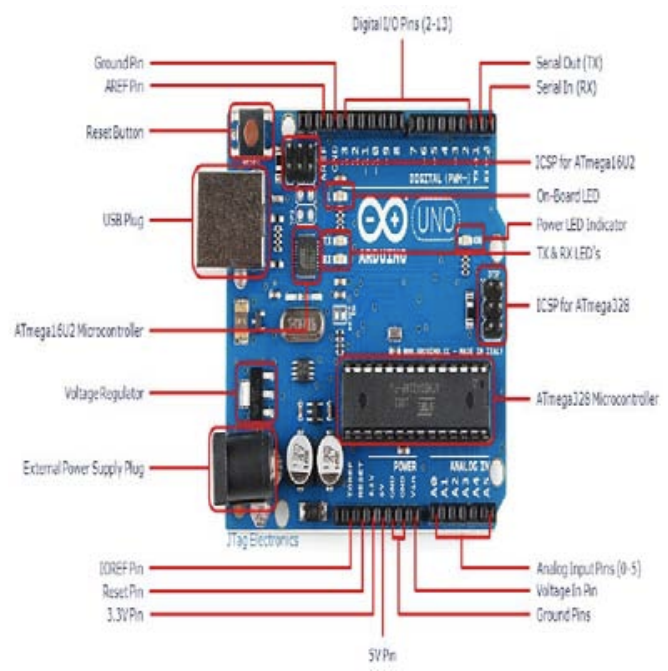

Figure 1 : Arduino UNO Board

Bluetooth module(HC-05)

This bluetooth module[3] (Figure.2) enables a user to wirelessly transmit $\&$ receive serial data at the same time . It 
helps us to transfer the signal from our application to the Arduino UNO Board. One can simply use it to establish a connection between MCU or embedded project and PC for data transfer.

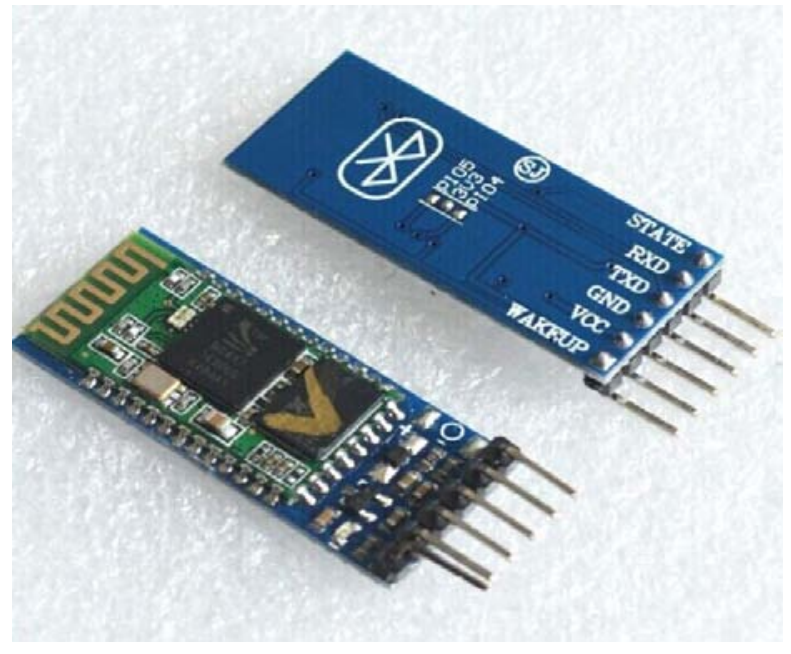

Figure 2 : Bluetooth module

\section{Servo motor}

It is [4] (Figure 3.) simple a DC motor that helps in angular rotations. We have used servo motor in our project to open the door of a car at certain angle.

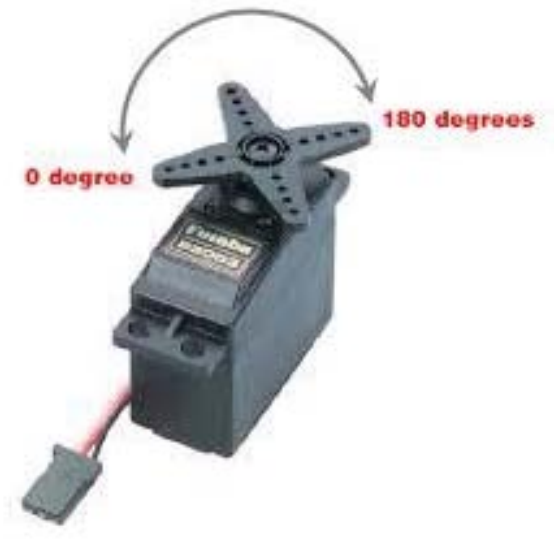

Figure 3 : Servo Motor

\section{RELATED WORK}

Mobiles [5] are very important in our daily life. So, we have developed a system that can interact with android mobiles. Here, Android device can communicate with arduino IDE via bluetooth module.

Arduino Board can read an input,light will glow on the sensor,thus, turns it to output i.e, turning an LED on.

The problem it addresses is that there is a lot of time when people misplace their car keys and they want to access the car for obtaining something lying in their car. Our system would allow them to unlock their car doors with the help of an application which would help them in taking the required item out of the car without the use of the car keys.

\section{PROPOSED WORK}

In Vehicular Auto locking system an application is developed to lock, unlock and show the lock status of the vehicle on windows platform which will run on windows phone operating system. It will allow only registered users to use the system. The application will also provide new users to ability to register themselves as authorized user of the system which will allow them to access the system and use services provided in the system. It is used when you have misplaced the key of the vehicle and you want to open the doors of your car. It will work in the way that if you click on open button, then signals will be sent from the application to the vehicle doors with the help of an Arduino chip.

\section{HARDWARE INTERFACES}

1) Arduino UNO board: Arduino Uno simply reads and input and gives corresponding ouput, thus, turning an LED on.

In our project, Aduino UNO sends a signal to servo motor,i.e, turning the motor on.

2) Arduino compatible USB cable: USB means 'Universal Serial Bus'. It helps us to connect computers to peripherals such as printers,scanners etc.

\section{SOFTWARE INTERFACES}

1) Arduino programming IDE

The "Arduino language" is simply[6] C++ (and therefore also C). All the standard system libraries are written in $\mathrm{C} / \mathrm{C}++$ and the IDE uses the gcc g++ compiler.

\section{2) Android Studio IDE}

This IDE provides various tools for developers to make an applications for Android phones.

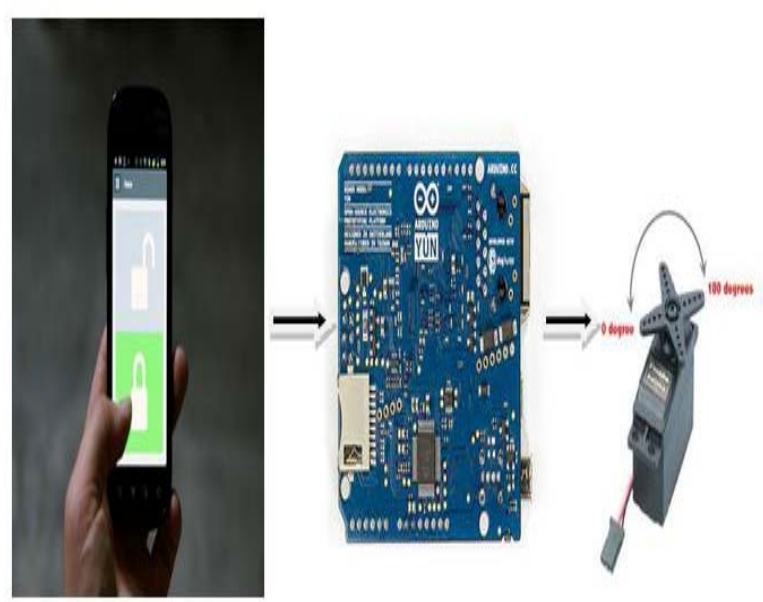

Figure 4 : Represents data flow between android application and servo motor

The Figure 4. [7] represents the secenario in which the data flows from the android application to the motor. When the user of our proposed system touches the lock button on an android smartphone, a signal is transmitted from the smartphone with the help of a Bluetooth module(HC-05) to arduino board. This arduino board transmits the signal required for servo motor to perform a desired operation, that is, locking and unlocking vehicle doors. 
Table 1 : System Components Functions

\begin{tabular}{|l|l|l|}
\hline Sl. No. & Components & Operation \\
\hline 1. & $\begin{array}{l}\text { Arduino UNO } \\
\text { Board }\end{array}$ & $\begin{array}{l}\text { Data Processing } \\
\text { and Control } \\
\text { Unit }\end{array}$ \\
\hline 2. & $\begin{array}{l}\text { Bluetooth } \\
\text { module (HC- } \\
\text { 06) }\end{array}$ & $\begin{array}{l}\text { Connects } \\
\text { applications to } \\
\text { Arduino. }\end{array}$ \\
\hline 3. & LED & $\begin{array}{l}\text { Acts as an } \\
\text { indicator. }\end{array}$ \\
\hline 4. & Battery pack & $\begin{array}{l}\text { Supplies power } \\
\text { to the system for } \\
\text { functioning }\end{array}$ \\
\hline 5. & Servo Motor & $\begin{array}{l}\text { Rotates for } \\
\text { locking and } \\
\text { unlocking doors }\end{array}$ \\
\hline 6. & $\begin{array}{l}\text { Android } \\
\text { Application }\end{array}$ & $\begin{array}{l}\text { Facilitates } \\
\text { commands for } \\
\text { locking and } \\
\text { unlocking }\end{array}$ \\
\hline
\end{tabular}

\section{SOFTWARE PLATFORM}

In the Figure.5, First of all we have to start the application and it will display login details, register it and then on the next page, we have lock and unlock buttons. After clicking on any button,signals will move forward through Arduino Uno Board and performs the required operation.

The Programming Language [8] used in Arduino IDE is based on $\mathrm{C}$ programming Language in which a sketch is created for implementing a required/desired task. Android application is developed using Android Studio which is an application development IDE(Integrated Development Environment) provide by the well-known software company Google.

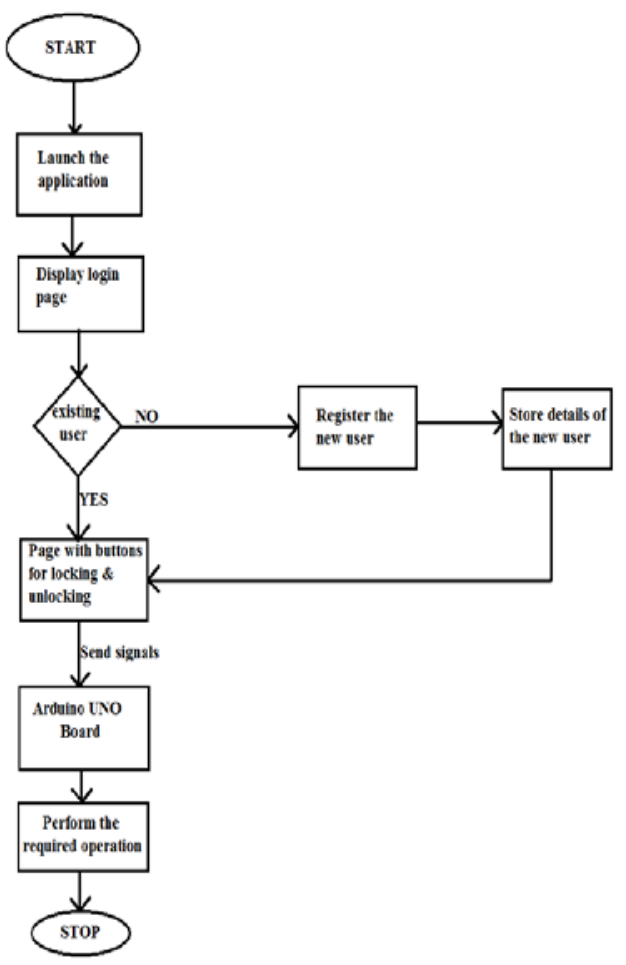

Figure 5 : Data Flow Diagram

\section{CONCLUSION AND FUTURE WORK}

The designing of vehicular auto locking system ended up successfully with the completion of both unlock and lock capability of door by an android application with the help of an Arduino UNO Board.[9] The Bluetooth module enables the application to interact with the arduino board. The major advantage here is the usage of an Arduino UNO board which can be easily used by an android application for effective communication between application and prototype developed with the help of an arduino board. In Future, this project can be further enhanced with GPRS for performing locking and unlocking operations from certain supported locations.

At present, there is no such system available on the Google play store for locking and unlocking vehicle doors with the help of a smartphone. The proposed system will be capable of only locking \& unlocking the vehicle doors with the help of android phone application, but in future, improvements can be made to this application to enable it to do other tasks such as starting the engine of the vehicle using some security feature so that no unauthorized person can start the vehicle.

\section{REFERENCES}

[1] Mrunal Sakhare, Sagar Ganer, Mona Mulchandani, "Car Remote Locking Via Bluetooth Using ANDROID”, published in International Research Journal of Engineering and Technology (IRJET), Volume: 02 Issue: 09,Dec-2015

[2] Badamasi, Y. A. (2014, September). The working principle of an Arduino. In Electronics, Computer and Computation (ICECCO), 2014 11th International Conference on (pp. 1-4). IEEE.

[3] Singh, G., \& Singh, I. (2014). Android os based wireless data acquisition system via bluetooth. IJRET, 3(06).

[4] Kleefeldt, F., \& Krause, L. (1979). U.S. Patent No. 4,135,377. Washington, DC: U.S. Patent and Trademark Office.

[5] Neelam Majgaonkar,Ruhina Hodekar,Priyanka Bandagale, “ Automatic Door Locking System”, published in International Journal Of Engineering Development And Research, Volume 4, Issue 1, 2016

[6] Noble, J. (2009). Programming Interactivity: A Designer's Guide to Processing, Arduino, and Openframeworks. " O'Reilly Media, Inc.".

[7] Mrunal Sakhare, SagarGaner, Mona Mulchandani,( 2015):Car Remote Locking Via Bluetooth Using ANDROID, International Research Journal of Engineering and Technology (IRJET) e-ISSN: 2395-0056 Volume: 02 Issue: 09 Dec-2015 www.irjet.net p-ISSN: 2395-0072.

[8] Servo Motor control and Arduino, Future Electronics Ltd, Egypt.

[9] Sakhare, M., \& SagarGaner, M. M. (2015). Car Remote Locking Via Bluetooth Using ANDROID. International Research Journal of Engineering and Technology (IRJET) eISSN, 2395-0056. 